\title{
Jasmonic Acid Signaling Pathway in Plants
}

\author{
Jingjun Ruan ${ }^{1,2} \oplus$, Yuexia Zhou ${ }^{1}$, Meiliang Zhou ${ }^{2}$, Jun Yan ${ }^{3}$, Muhammad Khurshid ${ }^{2,4}$, \\ Wenfeng Weng ${ }^{1}$, Jianping Cheng ${ }^{1}$ and Kaixuan Zhang ${ }^{2, *}$ \\ 1 College of Agriculture, Guizhou University, Guiyang 550025, China; jjruan@gzu.edu.cn (J.R.); \\ zhouyuexiagui@hotmail.com (Y.Z.); wenfengweng@hotmail.com (W.W.); jpcheng@gzu.edu.cn (J.C.) \\ 2 Institute of Crop Sciences, Chinese Academy of Agricultural Sciences, Beijing 100081, China; \\ zhoumeiliang@caas.cn (M.Z.); khurshid.ibb@pu.edu.pk (M.K.) \\ 3 Schools of Pharmacy and Bioengineering, Chengdu University, Chengdu 610106, China; \\ yanjun62@cdu.edu.cn \\ 4 Institute of Biochemistry and Biotechnology, University of the Punjab, Lahore 54590, Pakistan \\ * Correspondence: zhangkaixuan@caas.cn; Tel./Fax: +86-10-8210-6368
}

Received: 17 April 2019; Accepted: 7 May 2019; Published: 20 May 2019

\begin{abstract}
Jasmonic acid (JA) and its precursors and dervatives, referred as jasmonates (JAs) are important molecules in the regulation of many physiological processes in plant growth and development, and especially the mediation of plant responses to biotic and abiotic stresses. JAs biosynthesis, perception, transport, signal transduction and action have been extensively investigated. In this review, we will discuss the initiation of JA signaling with a focus on environmental signal perception and transduction, JA biosynthesis and metabolism, transport of signaling molecules (local transmission, vascular bundle transmission, and airborne transportation), and biological function (JA signal receptors, regulated transcription factors, and biological processes involved).
\end{abstract}

Keywords: jasmonic acid; signaling pathway; environmental response; biological function

\section{Introduction}

Plants undergo many physiological changes to cope with biotic and abiotic stress. The survival of plants mainly depends on their ability to adapt in a varying environment through signaling networks [1]. These networks establish connections between the environmental signals and cell responses [2]. Plant hormones play major roles in the establishment of signaling networks to regulate plant growth and stress-related responses. Jasmonic acid (3-oxo-2-2'-cis-pentenyl-cyclopentane-1-acetic acid, abbreviated as JA) is an endogenous growth-regulating substance found in higher plants. JA and its methyl ester (MeJA) and isoleucine conjugate (JA-Ile) are derivatives of a class of fatty acids and are collectively known as jasmonates (JAs). Initially identified as a stress-related hormone, JAs are also involved in the regulation of important growth and developmental processes [3,4]. For example, JAs can induce stomatal opening, inhibit Rubisco biosynthesis, and affect the uptake of nitrogen and phosphorus and the transport of organic matter such as glucose. In particular, as a signaling molecule, JAs can effectively mediate responses against environmental stresses by inducing a series of genes expression [5]. JAs and salicylic acid (SA)-mediated signaling pathways are mainly related to plant resistance, prompting plant responses to external damage (mechanical, herbivore, and insect damage) and pathogen infection, thereby inducing resistance gene expression. In this review, the initiation, transmission, and biological functions of jasmonic acid signaling are introduced from the point of view of environmental signal molecules. 


\section{Initiation of Jasmonic Acid Signaling}

\subsection{Signal Perception and Transduction}

In the last decades, a large number of studies have been conducted on how biotic and abiotic stress signals are perceived by plants and the biosynthesis of JA is initiated. In tomato (Lycopersicon esculentum), Pearce et al. in 1991 found a systemin that responded to mechanical damage such as insect damage [6]. Systemin is a polypeptide signal molecule consisting of 18 amino acids derived from a precursor protein consisting of 200 amino acids: prosystemin [7]. After the tomato is mechanically damaged, the prosystemin is hydrolyzed into a systemin, which can be transported to other cells via the apoplast and combined with the cell surface receptor SR160 (a protein rich in leucine repeat units) to finally activate the JA signaling pathway [8,9]. In addition to the traumatic signals, oligosaccharide signals induced by pathogens and fungal elicitors were also found in tomatoes, which ultimately activate the JA signaling pathway. It is speculated that the mechanism of action of oligosaccharides has a similar pathway to that of the systemin, but the specific mechanism of induction is still unclear [10,11].

Later, a polypeptide having the same function as a systemin, AtPEP1, consisting of 23 amino acids, was also found in Arabidopsis thaliana. Similar to the production of systemin, mechanical damage or pathogen infection promotes the hydrolysis of the precursor protein PROPEP1 (consisting of 92 amino acids) to AtPEP1, which binds to the receptor PEPR1 (an enzyme rich in leucine repeat units) on the plasma membrane, which ultimately activates the JA signaling pathway [12].

The process by which systemin and AtPEP1 bind to the receptor to activate the JA signaling pathway is complex. It is known that the most important process is to activate phospholipase on the plasma membrane, and then the phospholipase acts on the membrane to release linolenic acid (a precursor of JA synthesis) from the phospholipid [13]. However, the mechanism by which systemin activates phospholipase is unclear. So far, several phospholipases that can be induced by systemin and AtPEP1 have been identified, including PLA2 in tomato and DAD1, DGL, and PLD in Arabidopsis, and these phospholipases have similar mechanisms of action [14-16].

\subsection{Synthesis and Metabolism of Jasmonate Compounds}

Biosynthesis of JAs has been studied in a variety of monocotyledonous and dicotyledonous plants during the last decades. Most of the work is done in the model plants Arabidopsis thaliana and L. esculentum (tomato). So far, various enzymes in the JAs synthetic pathway have been identified, and our knowledge of the relationship between the JA synthesis pathway and other metabolic pathways is gradually improving (Figure 1). In Arabidopsis, there are three pathways for the synthesis of JAs, including the octadecane pathway starting from $\alpha$-linolenic acid (18:3) and the hexadecane pathway starting from hexadecatrienoic acid (16:3) [17]. All three pathways require three reaction sites: the chloroplast, peroxisome, and cytoplasm. The synthesis of 12-oxo-phytodienoic acid (12-OPDA) or deoxymethylated vegetable dienic acid (dn-OPDA) from unsaturated fatty acid takes place in the chloroplast, which is then converted to JA in the peroxisome. In the cytoplasm, JA is metabolized into different structures by various chemical reactions, such as MeJA, JA-Ile, cis-jasmone (CJ), and 12-hydroxyjasmonic acid (12-OH-JA). 


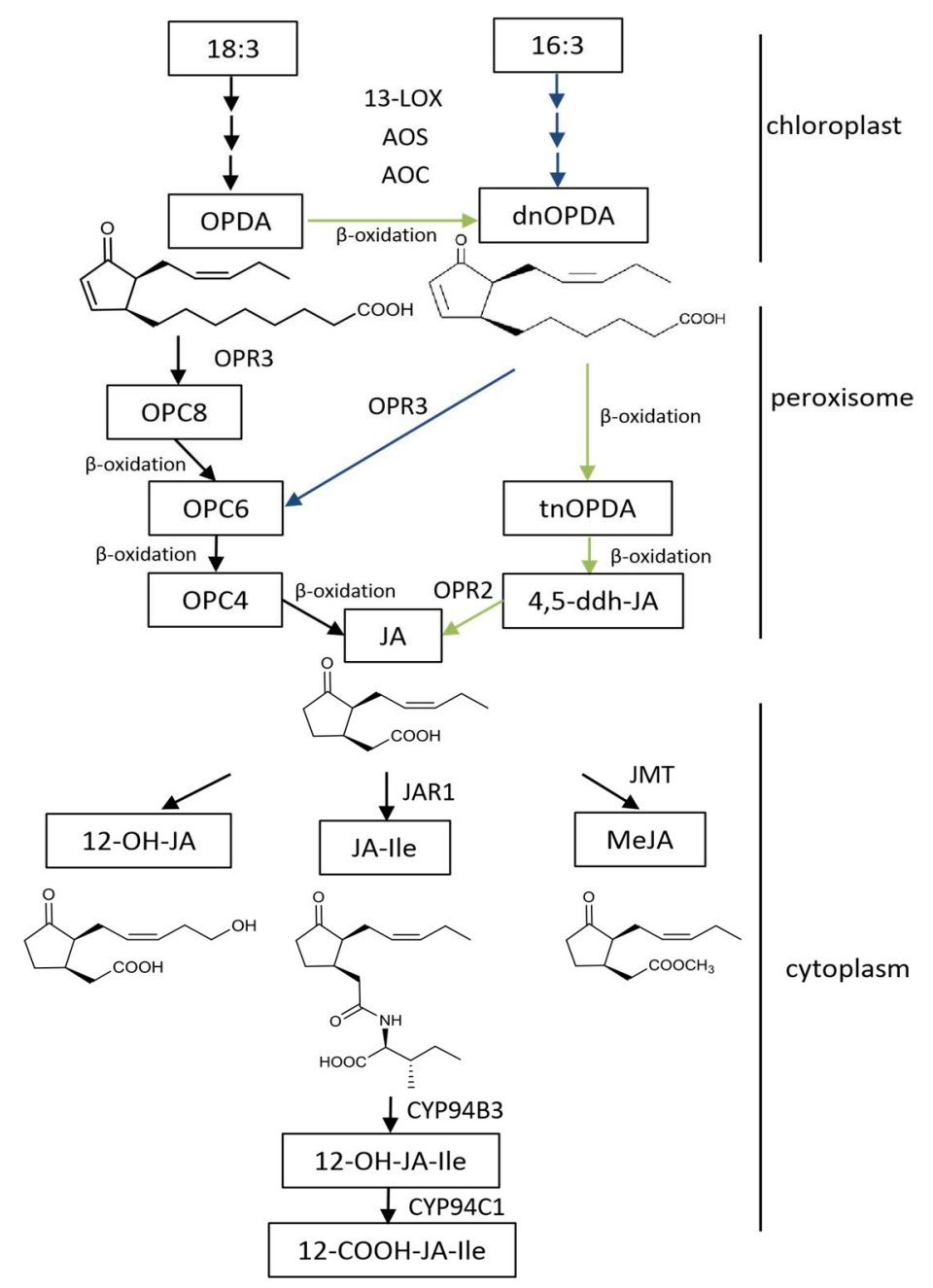

Figure 1. Scheme of the JAs biosynthesis pathway in Arabidopsis thaliana. The enzymes and the intermediates are indicated as follows: LOX for lipoxygenase, AOS for allene oxide synthase, AOC for allene oxide cyclase, OPR3 for OPDA reductase, JAR1 for jasmonate resistant 1, JMT for JA carboxyl methyltransferase; 18:3 for $\alpha$-linolenic acid, 16:3 for hexadecatrienoic acid, OPDA for 12-oxo-phytodienoic acid, dnOPDA for dinor-12-oxo-phytodienoic acid, OPC8 for 8-(3-oxo-2-(pent-2-enyl)cyclopentyl) octanoic acid, OPC6 for 6-(3-oxo-2-(pent-2-enyl)cyclopentyl) hexanoic acid, OPC4 for 4-(3-oxo-2-(pent-2-enyl)cyclopentyl) butanoic acid, tnOPDA for tetranor-OPDA, 4,5-ddh-JA for 4,5-didehydrjasmonate, JA for jasmonic acid, JA-Ile for jasmonoyl-L-isoleucine, and MeJA for methyl jasmonate.

\section{Transmission of the Jasmonic Acid Signal}

The defense response triggered by a traumatic signal can result in a local defense response near the wound and/or a systemic acquired resistance (SAR) at the uninjured site, and/or even induced defense responses from adjacent plants. In these defense responses, short-distance transmission and long-distance transmission of JA signals are involved [18]. With the studies in the area of mechanisms of hormone signaling networks, it has been found that salicylic acid, ethylene, auxin, and other plant hormones interact with JA to regulate plant adaptation to the environment. At present, the understanding of complex regulatory networks and metabolic processes after plants perceive environmental signals is still very limited. 


\subsection{Short-Distance Signal Transmission}

In plants, mechanical damage or insect feeding can cause rapid and transient accumulation of JA and JA-Ile at the site of injury, thereby activating the expression of defense genes surrounding the wound and producing a local defense response. In the local defense response, there are two ways of short-distance transmission of the JA signal. First, the systemin produced by the wounding acts as a signaling molecule, which is transmitted to the adjacent site through the apoplast and phloem to activate the JA cascade reaction pathway. Second, JA and JA-Ile induced by systemin act as signals and are transported to adjacent sites for defensive responses [19].

\subsection{Long-Distance Signal Transmission}

So far, it is known that the long-distance transmission of JA signals is via vascular bundle transmission and/or airborne transmission.

\subsubsection{Vascular Bundle Transmission}

Previously, many researchers believed that systemin functions directly in the long-distance signal transmission and is a mobile signal molecule. However, a series of grafting experiments using tomato jasmonate-insensitive mutant (jai1), systemin-insensitive mutant (spr1), and the JAs biosynthesis deletion mutants spr2 and $a c x 1 A$ demonstrated that the systemin was not the systemically transmitted signal [19]. After the induction of the synthesis of JA, JA and MeJA are systemically transmitted in plants [20]. Thorpe et al. demonstrated by radioisotopic labeling experiments that MeJA can be transferred to phloem and xylem in vascular bundles [21]. Some work has also shown that JAs are not simply transported along the vascular bundle, but are accompanied by resynthesis of JAs during transport [20]. The localization of various JA synthetases (such as LOX, AOS, etc.) was also found in the companion cell-sieve element complex (CC-SE) of tomato vascular bundles [22], and the sieve molecules in the phloem have the ability to form the JA precursor OPDA [23]. Recently, Koo et al. [24] found that the systemic JA and JA-Ile caused by injury induction are not all transferred from the injured site, at least part of which is resynthesized and cascading cycles in the uninjured site produce more JA-Ile, which was later confirmed by Larrieu et al. [25].

\subsubsection{Airborne Transmission}

It was found that the flow rate of the tomato phloem signal is $1-5 \mathrm{~cm}$ per hour [26], but the accumulation of JA and JA-Ile can be detected in the whole plant within 15 min after mechanical damage [27]. In the 1990s, ring-cutting experiments demonstrated that although the vascular bundle transmission was blocked, there was still a rapid and strong defense gene expression in the distal leaves [27]. A large number of studies showed that in addition to vascular bundle transmission, there are other long-distance transmission routes for JA signals. Compared with JA, which has difficulty in penetrating the cell membrane without carrier assistance, MeJA easily penetrates the cell membrane and has strong volatility, and thus can be spread by airborne diffusion to distant leaves and adjacent plants [28]. It has been confirmed in a range of plants, such as Arabidopsis thaliana [20], Nicotiana tabacum [29], Phaseolus lunatus [30], and Artemisia kawakamii [31], that MeJA can be transmitted by air between damaged and undamaged leaves or between adjacent plants.

\section{Perception of the Jasmonic Acid Signal and Induction of Response}

\subsection{Jasmonic Acid Receptor}

The nuclear transport mechanism of JAs was systematically analyzed by means of molecular genetics, molecular biology, biochemistry, and cell biology. The ABC transporter AtJAT1/AtABCG16 with JAs transport ability was screened by a yeast system [32]. Radioactive isotope uptake experiments and autoradiography experiments showed that AtJAT1/AtABCG16 acts as a high-affinity transporter 
to regulate the subcellular distribution of JAs [32]. AtJAT1/AtABCG16 is localized on the nuclear and plasma membranes of plant cells and mediates the transport of JAs across the plasma membrane and the bioactive JA-Ile across the inner membrane of the nuclear membrane to activate JA responses at low concentration. When the concentration of JAs is high, the function of the JA transporter on the cytoplasmic membrane is dominant, which reduces the intracellular JA and JA-Ile concentrations to desensitize the JA signal. The JAs signaling pathway is activated in other cells by transporting JA to the apoplast. AtJAT1/AtABCG16 can rapidly regulate the dynamics of JA/JA-Ile in cells, which leads to the quick transport of JA-Ile into the nucleus when the plant is under stress, as well as the quick desensitization of the JA signal to avoid the inhibition of plant growth and development by the defense response (Figure 2).

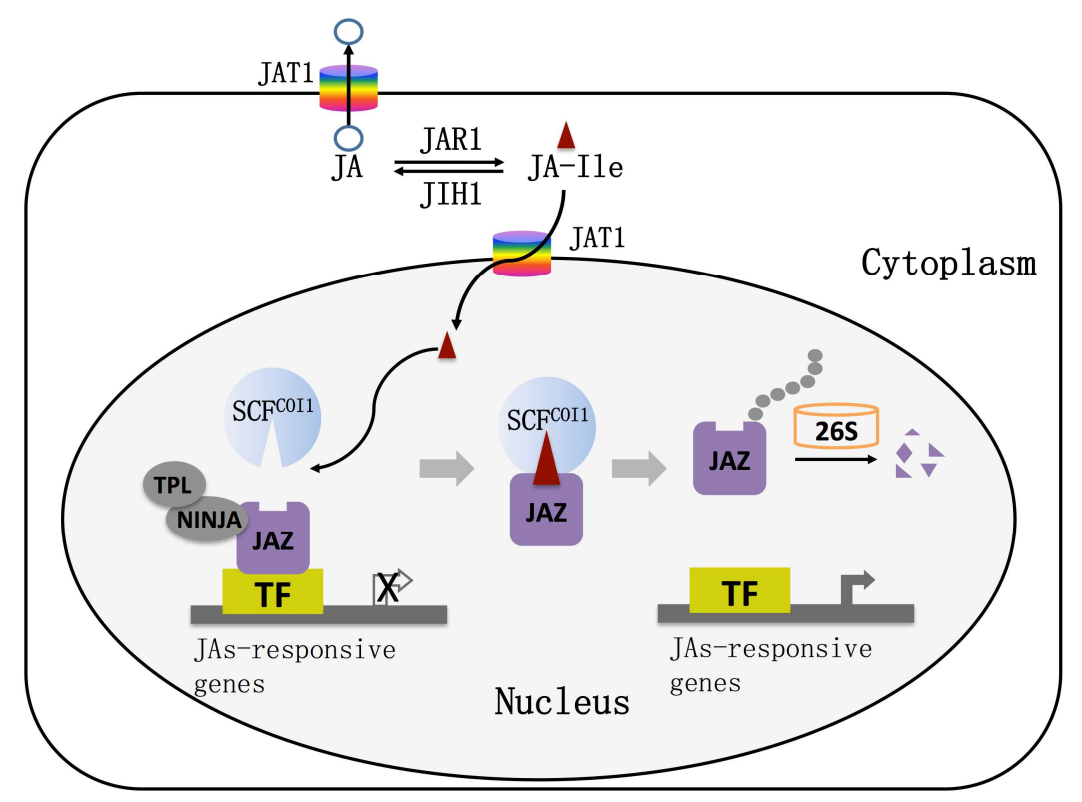

Figure 2. The working model of jasmonic acid transport and signaling pathway. JAT1: jasmonic acid transfer protein1; SCF: Skp1, Cullin and F-box proteins; COI1: coronatine insensitive1; JAZ: jasmonate ZIM-domain protein; TF: transcription factor; TPL: TOPLESS protein; NINJA: NOVEL INTERACTOR OF JAZ; 26S: 26S proteasome.

The understanding of JA receptors has undergone a complex process. In 1994, Feys first found that the Arabidopsis coronatine insensitive1 (coi1) mutant lost all responses to JA [33], and further studies indicated that the COI1 gene encodes an F-box protein that is a component of E3 ubiquitin ligase [34]. In this case, COI1 associates with the SKP1 protein and Cullin protein to form the SCF-type E3 ubiquitin ligase that is referred to as $\mathrm{SCF}{ }^{\mathrm{CO} I 1}$, which targets the repressor proteins for degradation by ubiquitination $[34,35]$. The discovery of COI1 protein is of great significance for the study of theJA signaling pathway.

It was once thought that COI1 is the receptor for jasmonic acid signaling in cells, until the discovery of a jasmonate Zinc finger Inflorescence Meristem (ZIM)-domain (JAZ) protein family, which gave a new understanding of the jasmonic acid signal transduction pathway. In 2007, three research groups simultaneously found that JAZ proteins act as repressors in the JA signaling pathway [36-38]. To date, 13 JAZ proteins have been found in Arabidopsis, most of which have two conserved domains, Jas and ZIM [39]. The JAZ protein interacts with COI1 via the Jas domain and interacts with MYC2 via the ZIM domain [40]. Therefore, many researchers believe that JAZ proteins are the target protein of COI1 and the degradation of JAZ proteins is a key step to relieve the inhibition of the JAs pathway. However, in 2010, Sheard et al. proposed different views on JAs receptors through the analysis of crystal structure and confirmed that the COI1-JAZ complex is a high-affinity receptor for the bioactive JA-Ile; that is, COI1 and JAZ are coreceptors of JA signaling [41]. It is currently believed that plants perceive stimuli 
from the external environment to generate JA-Ile, which promotes the interaction between COI 1 and JAZ proteins. Subsequently, JAZ proteins are degraded after being transferred to the $26 \mathrm{~S}$ proteasome, and simultaneously, transcription factors (TFs) are released to activate the expression of downstream genes (Figure 2).

\subsection{Jasmonic Acid Signal-Regulated Transcription Factor}

JA-Ile activates the MYC transcription factors by directly binding to JAZ and COI1, which results in the degradation of JAZ through the $26 \mathrm{~S}$ proteasome pathway (Figure 2). Recent studies have shown that the MYB transcription factors also bind with JAZ repressors and can be activated by the degradation of JAZ in the presence of JA-Ile. In addition, several other transcription factors (TFs) such as NAC, ERF, and WRKY are also involved in the JA signaling. These JA-responsive TFs regulate the expression of many genes involved in the growth and development of plants, and especially the responses and adaptation of plants to the environment (Figure 3). Studies have also shown that JA signaling can also induce the MAP kinase cascade pathway [42], calcium channel [43], and many processes that interact with signaling molecules such as ethylene, salicylic acid, and abscisic acid to regulate plant growth and development [44].

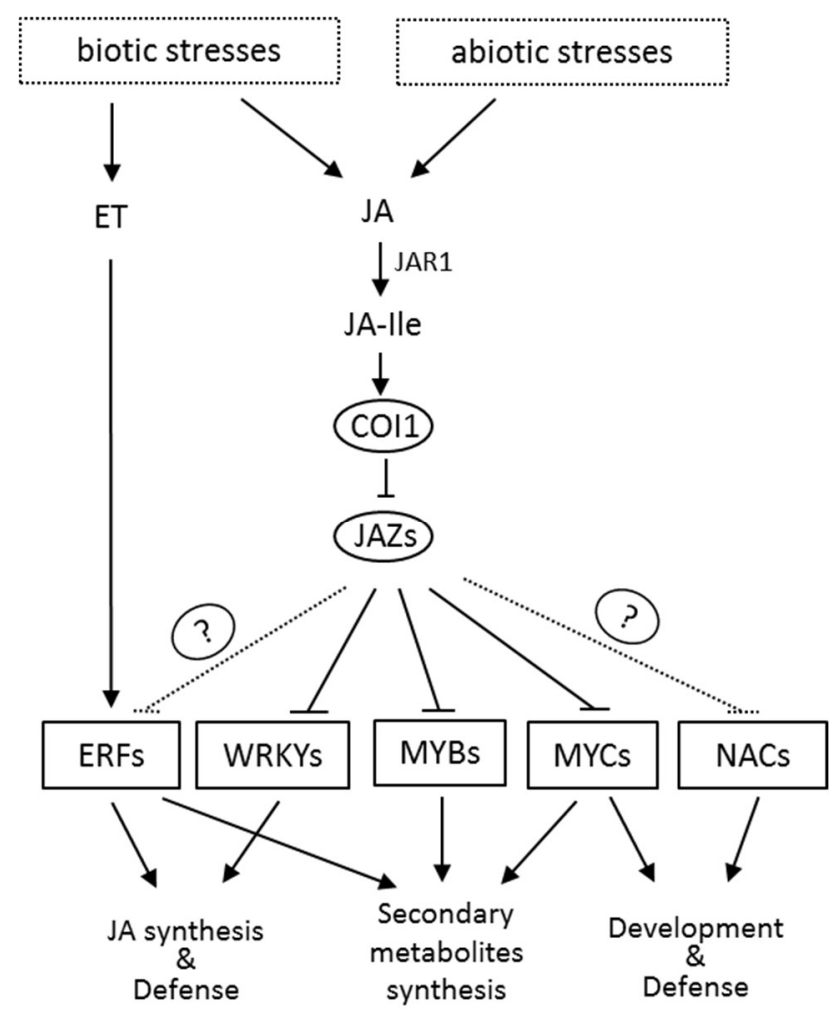

Figure 3. The regulation network of the jasmonic acid signaling pathway. Biotic and abiotic stresses induce the synthesis of JA, which can be converted to the biologically active JA-Ile by JAR1. Perception of JA-Ile by its receptor COI1 triggers the degradation of JAZ repressors, leading to the release of downstream transcription factors and the regulation of JAs-responsive genes in various processes. The question marker indicates an adaptor protein which is not identified yet.

\subsubsection{MYC Transcription Factor}

The basic helix-loop-helix (bHLH) transcription factor MYC2 is a well-known regulatory protein encoded by the JIN1 gene. Most members of the JAZ protein family interact with MYC2 [45]. For a long time, it was believed that only the MYC2 protein can directly interact with the JAZ protein. In 2011, Fernandez-Calvo et al. identified that two other bHLH proteins, MYC3 and MYC4, share high sequence similarity with MYC2, suggesting they probably have similar functions. Indeed, MYC3 and MYC4 
interact with JAZ proteins in vivo and in vitro, have similar DNA-binding specificity to MYC2, and act synergistically and distinctly with MYC2 [46]. A closely related TF, MYC5 (bHLH28), is induced by JAs and required for male fertility [47]. Besides transcriptional activators, JA-associated MYC2-like (JAM) proteins, JAM1, JAM2, and JAM3, were discovered as transcriptional repressors via forming protein-protein interactions with JAZs to regulate JAs responses [48].

\subsubsection{MYB Transcription Factor}

Most of the JAs-responsive MYB TFs belong to the R2R3-MYB family, which are widely distributed in plants and required for many processes. Schmiesing et al. showed that MYB51 and MYB34 regulate the synthesis of tryptophan and glucosinolates and act downstream of MYC2 [45]. However, many studies have found that MYB TFs can directly bind to JAZ proteins, indicating the release from JAZs to activate their target genes. For instance, in Arabidopsis, MYB21 and MYB24 are key factors in stamen and pollen maturation [49], and MYB75 can positively regulate the anthocyanin accumulation and trichome initiation [50]. Recently, a set of MYB TFs, MYB11, MYB13, MYB14, MYB15, and MYB16, were identified as repressors in the regulation of rutin biosynthesis in tartary buckwheat [51,52].

\subsubsection{NAC Transcription Factor}

ATAF1 and ATAF2 TFs in the Arabidopsis NAC family are both induced by JA signaling and involved in plant resistance to drought, salt stress, Botrytis cinerea, and other pathogens [53]. At the same time, ATAF1 and ATAF2 have an important regulatory effect on oxidative stress, flowering, and pod development of plants [54]. Two other NAC TFs in Arabidopsis, ANAC019 and ANAC055, are also present downstream of the MYC2 protein and regulate seed germination, cell division, and the synthesis of secondary walls of cells [55]. In addition, ATAF1, ATAF2, ANAC019, and ANAC055 are also involved in the crosstalk between JA and SA signaling pathways [53-55].

\subsubsection{Ethylene-Responsive Factor (ERF) Transcription Factor}

Microarray experiments at the genetic level have confirmed that JA signaling can induce the transcription of many ERF genes. The first evidence for a link between AP2/ERF TFs and JA signaling was found in Catharanthus roseus. The JAs-induced ORCA proteins, ORCA2 and ORCA3, belong to the AP2/ERF-domain family and can activate the expression of monoterpenoid indole alkaloid biosynthesis genes [56]. Based on the observation of ORCAs, the Arabidopsis ERF proteins, ERF1 and ORA59, function dependently on JAs and/or ET for the defenses against Botrytis cinerea [57,58]. Moreover, ORA59, rather than ERF1, acts as the integrator of JAs and ET signals [58] and regulates the biosynthesis of hydroxycinnamic acid amides [59]. The JAs-induced ORA47 can activate the expression of the JAs biosynthesis gene $A O C 2$, indicating that ORA47 might act as an important regulator in the positive JAs-responsive feedback loop [60]. Moreover, JAs-responsive AtERF3 and AtERF4 act as repressors by not only down regulating their target genes' expression, but also interfering with the activity of other activators [61]. Interestingly, the activity of above TFs is not directly repressed by JAZ proteins, suggesting the presence of adaptors or corepressors in the JA signaling pathway.

\subsubsection{WRKY Transcription Factor}

WRKY transcription factors play an important regulatory role in plant development, senescence, and coping with environmental stress. In Arabidopsis, there are 89 members in the WRKY transcription factor family. It has been shown that some WRKY TFs are regulated by the JA signaling pathway, such as WRKY70 [62], WRKY22 [63], WRKY50 [64], WRKY57 [65], and WRKY89 [66]. These WRKY transcription factors are mostly associated with plant defense functions. In Nicotiana attenuata, two WRKY transcription factors, NaWRKY3 and NaWRKY6, regulate the expression of JAs biosynthesis-related genes ( $L O X, A O S, A O C$, and OPR) to increase the levels of JA and JA-Ile [67]. In addition, Arabidopsis WRKY57 interacts with the inhibitor JAZ4/JAZ8 in the JA signaling pathway and the inhibitor IAA29 
in the auxin signaling pathway, thereby regulating the interaction between JA and auxin-mediated signaling pathways and effects on plant leaf senescence [65].

\section{Biological Processes Involved in Jasmonic Acid Signaling}

\subsection{Environmental Responses Affected by Jasmonic Acid Signaling}

JA and its derivatives are plant signaling molecules closely related to plant defense and resistance to microbial pathogens, herbivorous insects, wounding, drought, salt stress, and low temperature. In addition to the traumatic signals, oligosaccharide signals induced by pathogens and fungal elicitors were also found in tomatoes, which ultimately activated the JA signaling pathway. Upon mechanical wounding in tomato, the prosystemin is hydrolyzed into a systemin, which can be transported to other cells via the apoplast and interacts with the cell surface receptor SR160 (a protein rich in leucine repeat units) to finally activate JAs responses. In this section, we will discuss the role of JA signaling in regulating plant responses in varying environments.

\subsubsection{Effect of Light on Jasmonic Acid Signal Changes}

To a large extent, the early development of plants is affected by light. It is observed that JA signaling mediates two aspects of the plant response to light: the photomorphogenesis of plants and the damage of plants by UVB. Red light/far-red light-mediated photomorphogenesis was observed in Arabidopsis and rice to be affected by JA signaling [68]. The involvement of the JA signaling pathway was also observed in blue light-mediated light morphogenesis in Arabidopsis and tomato [69,70]. Enhancement of UVB radiation induces the biosynthesis of JAs in the Nicotiana and Brassica genera to initiate the JA signaling pathway, and these processes are associated with chemical defenses of plants $[68,71]$.

\subsubsection{Effect of Temperature on Jasmonic Acid Signal Changes}

The JA signaling pathway is involved in the response and adaptation process of plants to low temperatures. Recent studies on bananas have shown that the MeJA treatment can significantly induce the expression of MYC-family TFs and many cold-responsive genes (MaCBF1, MaCBF2, MaCOR1, $M a K I N 2, M a R D 2, M a R D 5$, etc.) after cold storage, thereby reducing the damage of plants caused by cold [72]. It was also shown that the endogenous JA content of the banana (Musa acuminata) decreased slightly after low-temperature treatment, and the change was not significant [72]. However, in the cold, the MYC gene is activated rapidly in response to exogenous MeJA and resynthesizes a large amount of JAs in the plant body to protect against cold damage. In addition, studies in tomato (L. esculentum) [73], pomegranate (Punica granatum) [74], loquat (Eribotrya japonica) [75], mango (Mangifera indica) [76], and guava (Psidium guajava) [77] have shown that exogenous MeJA treatment can induce heat shock protein family transcription, increase antioxidant synthesis, reduce lipoxygenase activity, and increase plant resistance to cold damage (with $0{ }^{\circ} \mathrm{C}$ upper temperature). At present, there are relatively few reports on the JA signal involved in plant heat resistance, but JA is a key signal molecule for the formation of sesquiterpene induced by heat shock in eaglewood (Aquilaria sinensis) $[1,2,78]$.

\subsubsection{Effect of Drought on Jasmonic Acid Signal Changes}

Many studies have found that JA signaling pathways are involved in drought stress. In Arabidopsis thaliana [79] and citrus (Citrus paradisi $\times$ Poncirus trifoliate) [80], it was found that the increase of endogenous JA content after drought stress was rapid and transient, and then gradually decreased to the basal level with the prolonged stress. On the other hand, the application of exogenous JA can also effectively alleviate the damage caused by drought to plants. Peanut (Arachis hypogaea) seedlings treated with MeJA showed enhanced drought resistance [81]. It was also observed that MeJA treatment can improve drought resistance in rice (Oryza sativa) [82], soybean (Glycine max) [83], and broccoli (Brassica oleracea) [84] by adjusting metabolism. Studies on broad bean (Vicia faba) and barley (Hordeum vulgare) 
have shown that MeJA may regulate stomatal closure through $\mathrm{K}^{+}$channels, thereby increasing the ability of plants to resist drought $[85,86]$.

\subsubsection{Effect of Salt on Jasmonic Acid Signal Changes}

It was found that the endogenous JA content increased significantly after salt treatment in Arabidopsis thaliana [87], tomato (L. esculentum) [88], and potato (Solanum tuberosum) [89], among other plants. Moreover, JA content increased rapidly and persistently in salt-sensitive plants, while changes in JA content in salt-tolerant plants were not significant [89]. It has also been observed that exogenous JA can enhance the resistance of plants such as pepper (Capsicum annuum) [90] and verbena (Rupestris riparia) [91] to salt stress.

\subsubsection{Effect of $\mathrm{CO}_{2}$ Concentration on Jasmonic Acid Signal Changes}

Ballhorn et al. found that high concentrations of $\mathrm{CO}_{2}(500,700$, and $1000 \mu \mathrm{mol} / \mathrm{mol})$ led to an increase in the release of JAs (MeJA and cis-JA) into the environment in lima bean (P. lunatus) [92]. The induced defense of plants infested with nematodes may be affected by elevated $\mathrm{CO}_{2}$ concentrations, and $\mathrm{CO}_{2}$-induced changes in plant resistance may result in genotypic-specific responses of plants to nematodes under elevated $\mathrm{CO}_{2}$ conditions [93]. However, there are few studies on the JA signaling pathway in plants under the action of $\mathrm{CO}_{2}$.

\subsubsection{Effect of Ozone on Jasmonic Acid Signal Changes}

The endogenous JA content of wild-type Arabidopsis increased significantly after ozone treatment. Experiments with the ozone-sensitive mutants $r c d 1$ (radical-induced cell death 1) [94] and oji1 (ozone-sensitive and jasmonate-insensitive) [91,95] and the JA signal mutant jar1 [96] have shown that exogenous MeJA can inhibit the spread of programmed cell death caused by ozone. Repression of the JA signaling pathway causes the plant to have a more intense response to ozone. Application of exogenous MeJA also resulted in reduced sensitivity of the hybrid poplar (Populus maximowizii $\times$ P. trichocarpa) [97] and tomato (L. esculentum) [96] to ozone. However, recent studies on cotton (Gossypium hirsutum) have shown that MeJA exhibits inhibition of ozone damage diffusion only at high concentrations (volume fraction: 685) of ozone, accompanied by antagonism with ethylene [98].

\subsection{Gene Chip and Proteomics Studies on Jasmonic Acid Signal Changes}

RNA-seq and proteomics studies further confirm the involvement of the JA signaling pathway in regulating the physiological processes of plants. Systematic biological approaches such as using gene chip and proteomics can study various physiological processes of plants at the whole genome level, and thus analyze the relationship between various metabolic pathways. Jung et al. identified 137 genes with altered expression levels in MeJA-treated Arabidopsis using gene chip technology. Among them, 74 genes were upregulated, including JAs biosynthesis genes, various defense genes (such as pdf1.2, encoding genes of myrosinase-binding protein), oxidative stress genes (oxidases, glutathione transfer), aging-related genes, cell wall modification-related genes, hormone metabolism-related (such as ACC oxidase, responsible for ethylene synthesis) genes, and genes involved in storage, signal transduction, and primary and secondary metabolism. The 63 downregulated genes included photosynthesis-related genes (Rubisco enzyme gene, chlorophyll protein gene, early photoinduced protein gene), cold regulatory genes, drought-responsive genes, defense-responsive genes, plant growth and development-related genes, cell wall-modification -related genes, and some other unknown functional genes, etc. [99]. Chen et al. compared the protein content of Arabidopsis thaliana before and after MeJA treatment by proteomics and found 186 differentially expressed proteins. These proteins are involved in plant photosynthesis, carbohydrate metabolism, hormone metabolism, secondary metabolism, product transport, stress and defense, and gene transcription [100]. 


\section{Future Prospects}

In the last decades, the JA signaling pathway has been studied extensively, but our knowledge about the role of JA signaling in response to different environmental stimuli is limited. Environmental signals usually result in a complex response network regulated by multiple signaling pathways. The mechanism of action of JA signaling in plant-environment interaction is still not clear. A series of signal transduction pathways related to JAs biosynthesis and transmission are well known, but it has not been systematically studied how different environmental signals are perceived by plants and initiate JAs synthesis. Due to the large number of receptors and kinases on the cell membrane, different biotic and abiotic signals stimulate the activation of different enzymes, accompanied by a series of complex reactions, such as calcium channel and potassium channel opening. Therefore, the perception of environmental signals has still a lot of research space. The studies on JAs receptors has made great progress, and the JA signal transduction pathway has also been established, but there are still many questions regarding the regulatory process which need to be answered.

Author Contributions: J.R., J.C. and M.Z. designed the review; J.R., J.Y., M.K. and Y.Z. access to information; J.R., K.Z. and M.K. revised the manuscript; M.K., W.W. and K.Z. designed the chart; J.R., Y.Z. and K.Z. wrote the paper.

Funding: Financial support was given by the National Key R\&D Program of China “Intergovernmental International Science and Technology Innovation Cooperation/Hong Kong, Macao and Taiwan Science and Technology Innovation Cooperation" Key Project (No. 2017YFE0117600), the National Natural Science Foundation of China (No. 31660531 and 3180100249), and the Guizhou Science and Technology Support Project (No. 2018-2292).

Acknowledgments: We are very grateful to En-tang Tian (Guizhou University) for fruitful discussions on this work and Su-qin Zhang (National Wheat Improvement Center, Guizhou sub-center, University of Guizhou) for critical reading of the manuscript.

Conflicts of Interest: The authors declare no conflicts of interest.

\section{References}

1. Mur, L.A.; Kenton, P.; Atzorn, R.; Miersch, O.; Wasternack, C. The outcomes of concentration-Specific interactions between salicylate and jasmonate signaling include synergy, antagonism, and oxidative stress leading to cell death. Plant Physiol. 2006, 140, 249-262. [CrossRef] [PubMed]

2. Clarke, S.M.; Cristescu, S.M.; Miersch, O.; Harren, F.J.; Wasternack, C.; Mur, L.A. Jasmonates act with salicylic acid to confer basal thermotolerance in Arabidopsis thaliana. New Phytol. 2009, 182, 175-187. [CrossRef]

3. Wasternack, C.; Hause, B. Jasmonates: Biosynthesis, perception, signal transduction and action in plant stress response, growth and development. An update to the 2007 review in Annals of Botany. Ann. Bot. 2013, 111, 1021-1058. [CrossRef]

4. Campos, M.L.; Kang, J.H.; Howe, G.A. Jasmonate-triggered plant immunity. J. Chem. Ecol. 2014, 40, 657-675. [CrossRef] [PubMed]

5. Gupta, A.; Hisano, H.; Hojo, Y.; Matsuura, T.; Ikeda, Y.; Mori, I.C.; Kumar, M.S. Global profiling of phytohormone dynamics during combined drought and pathogen stress in Arabidopsis thaliana reveals ABA and JA as major regulators. Sci. Rep-UK 2017, 7, 4017. [CrossRef]

6. Pearce, G.; Strydom, D.; Johnson, S.; Ryan, C.A. A polypeptide from tomato leaves induces wound-inducible proteinase inhibitor proteins. Science 1991, 253, 895-897. [CrossRef]

7. Ryan, C.A.; Pearce, G. Systemins: A functionally defined family of peptide signals that regulate defensive genes in Solanaceae species. Proc. Natl. Acad. Sci. USA 2003, 100, 14577-14580. [CrossRef]

8. Li, C.; Liu, G.; Xu, C.; Lee, G.I.; Bauer, P.; Ling, H.Q.; Ganal, M.W.; Howe, G.A. The tomato suppressor of prosystemin-mediated responses2 gene encodes a fatty acid desaturase required for the biosynthesis of jasmonic acid and the production of a systemic wound signal for defense gene expression. Plant Cell 2003, 15, 1646-1661. [CrossRef]

9. Scheer, J.M.; Ryan, C.A. The systemin receptor SR160 from Lycopersicon peruvianum is a member of the LRR receptor kinase family. Proc. Natl. Acad. Sci. USA 2002, 99, 9585-9590. [CrossRef] [PubMed]

10. Stratmann, J.W.; Ryan, C.A. Myelin basic protein kinase activity in tomato leaves is induced systemically by wounding and increases in response to systemin and oligosaccharide elicitors. Proc. Natl. Acad. Sci. USA 1997, 94, 11085-11089. [CrossRef] [PubMed] 
11. Narváez-Vásqueza, J.; Florin-Christensen, J.; Ryan, C.A. Positional specificity of a phospholipase A activity induced by wounding systemin oligosaccharide elicitors in tomato leaves. Plant Cell 1999, 11, 2249-2260. [CrossRef] [PubMed]

12. Yamaguchi, Y.; Huffaker, A.; Bryan, A.C.; Tax, F.E.; Ryan, C.A. PEPR2 is a second receptor for the Pep1 and Pep2 peptides and contributes to defense responses in Arabidopsis. Plant Cell 2010, 22, 508-522. [CrossRef]

13. Hind, S.; Malinowski, R.; Yalamanchili, R.; Stratmann, J.W. Tissue-type specific systemin perception and the elusive systemin receptor. Plant Signal. Behav. 2010, 5, 42-44. [CrossRef] [PubMed]

14. Yan, L.; Zhai, Q.; Wei, J.; Li, S.; Wang, B.; Huang, T.; Du, M.; Sun, J.; Kang, L.; Li, C.B.; et al. Role of tomato lipoxygenase $\mathrm{D}$ in wound-induced jasmonate biosynthesis and plant immunity to insect herbivores. PLoS Genet. 2013, 9, e1003964. [CrossRef] [PubMed]

15. Ellinger, D.; Sting, N.; Kubigsteltig, I.I.; Bals, T.; Juenger, M.; Pollmann, S.; Berger, S.; Schuenemann, D.; Mueller, M.J. DGL and DAD1 lipases are not essential for wound- and pathogen induced jasmonate biosynthesis: Redundant lipases contribute to jasmonate formation. Plant Physiol. 2010, 153, 114-127. [CrossRef] [PubMed]

16. Turner, J.G.; Ellis, C.; Devoto, A. The jasmonate signal pathway. Plant Cell 2002, 14 (Suppl. 1), S153-S164. [CrossRef]

17. Chini, A.; Monte, I.; Zamarreño, A.M.; Hamberg, M.; Lassueur, S.; Reymond, P.; Weiss, S.; Stintzi, A.; Schaller, A.; Porzel, A.; et al. An OPR3-independent pathway uses 4,5-didehydrojasmonate for jasmonate synthesis. Nat. Chem. Biol. 2018, 14, 171-178. [CrossRef]

18. Ryan, C.A.; Moura, D.S. Systemic wound signaling in plants: A new perception. Proc. Natl. Acad. Sci. USA 2002, 99, 6519-6520. [CrossRef]

19. Truman, W.; Bennett, M.H.; Kubigsteltig, I.; Turnbull, C.; Grant, M. Arabidopsis systemic immunity uses conserved defense signaling pathways and is mediated by jasmonates. Proc. Natl. Acad. Sci. USA 2007, 104, 1075-1080. [CrossRef] [PubMed]

20. Heil, M.; Ton, J. Long-distance signaling in plant defense. Trends Plant Sci. 2008, 13, 264-272. [CrossRef]

21. Thorpe, M.R.; Ferrieri, A.P.; Herth, M.M.; Ferrieri, R.A. 11Cimaging: Methyl jasmonate moves in both phloem and xylem, promotes transport of jasmonate and of photoassimilate even after proton transport is decoupled. Planta 2007, 226, 541-551. [CrossRef]

22. Hause, B.; Stenzel, I.; Miersch, O.; Maucher, H.; Kramell, R.; Ziegler, J.; Wasternack, C. Tissue-specific oxylipin signature of tomato flowers: Allene oxide cyclase is highly expressed in distinct flower organs and vascular bundles. Plant J. 2000, 24, 113-126. [CrossRef] [PubMed]

23. Hause, B.; Hause, G.; Kutter, C.; Miersch, O.; Wasternack, C. Enzymes of jasmonate biosynthesis occur in tomato sieve elements. Plant Cell Physiol. 2003, 44, 643-648. [CrossRef] [PubMed]

24. Koo AJ, K.; Gao, X.; Jones, A.D.; Howe, G.A. A rapid wound signal activates systemic synthesis of bioactive jasmonates in Arabidopsis. Plant J. 2009, 59, 974-986. [CrossRef] [PubMed]

25. Larrieu, A.; Vernoux, T. Q\&A: How does jasmonate signaling enable plants to adapt and survive? BMC Boil. 2016, 14, 79 .

26. Nelson, C.E.; Walker-simmons, M.; Makus, D.; Zuroske, G.; Graham, J.; Ryan, C.A. Regulation of synthesis and accumulation of proteinase-inhibitors in leaves of wounded tomato plants. ACS Symp. Ser. 1983, 208, 103-122.

27. Malone, M. Rapid, long-distance signal transmission in higher plants. Adv. Bot. Res. 1996, 22, $163-228$.

28. Farmer, E.E.; Ryan, C.A. Interplant communication: Airborne methyl jasmonate induces synthesis of proteinase inhibitors in plant leaves. Proc. Natl. Acad. Sci. USA 1990, 87, 7713-7716. [CrossRef]

29. Park, S.W.; Kaimoyo, E.; Kumar, D.; Mosher, S.; Klessig, D.F. Methyl salicylate is a critical mobile signal for plant systemic acquired resistance. Science 2007, 318, 113-116. [CrossRef]

30. Kost, C.; Heil, M. The defensive role of volatile emission and extra-floral nectar secretion for lima bean in nature. J. Chem. Ecol. 2008, 34, 2-13. [CrossRef]

31. Karban, R.; Baldwin, I.T.; Baxter, K.J.; Laue, G.; Felton, G.W. Communication between plants: Induced resistance in wild tobacco plants following clipping of neighboring sagebrush. Oecologia 2000, 125, 66-71. [CrossRef]

32. Li, Q.; Zheng, J.; Li, S.; Huang, G.; Skilling, S.J.; Wang, L.; Li, L.; Li, M.; Yuan, L.; Liu, P. Transporter-mediated nuclear entry of jasmonoyl-Isoleucine is essential for jasmonate signaling. Mol. Plant. 2017, 10, 695-708. [CrossRef] [PubMed] 
33. Feys, B.; Benedetti, C.E.; Penford, C.N.; Turner, J.G. Arabidopsis mutants selected for resistance to the phytotoxin coronatine are male sterile, insensitive to methyl jasmonate, and resistant to a bacterial pathogen. Plant Cell 1994, 6, 751-759. [CrossRef]

34. Xie, D.X.; Feys, B.F.; James, S.; Nieto-Rostro, M.; Turner, J.G. COI1: An Arabidopsis gene required for jasmonate-regulated defense and fertility. Science 1998, 280, 1091-1094. [CrossRef] [PubMed]

35. Zhai, Q.; Zhang, X.; Wu, F.; Feng, H.; Deng, L.; Xu, L.; Zhang, M.; Wang, Q.; Li, C. Transcriptional mechanism of jasmonate receptor COI1-mediated delay of flowering time in Arabidopsis. Plant Cell 2015, 27, 2814-2828. [CrossRef] [PubMed]

36. Chini, A.; Fonseca, S.; Fernandez, G.; Adie, B.; Chico, J.; Lorenzo, O.; Garcia-Casado, G.; Lopez-Vidriero, I.; Lozano, F.; Ponce, M. The JAZ family of repressors is the missing link in jasmonate signalling. Nature 2007, 448, 666-671. [CrossRef] [PubMed]

37. Thines, B.; Katsir, L.; Melotto, M.; Niu, Y.; Mandaokar, A.; Liu, G.; Nomura, K.; He, S.Y.; Howe, G.A.; Browse, J. JAZ repressor proteins are targets of the $\mathrm{SCF}^{\mathrm{CO} 1}$ complex during jasmonate signaling. Nature 2007, 448, 661-665. [CrossRef] [PubMed]

38. Yan, Y.; Stolz, S.; Chételat, A.; Reymond, P.; Pagni, M.; Dubugnon, L.; Farmer, E.E. A downstream mediator in the growth repression limb of the jasmonate pathway. Plant Cell 2007, 19, 2470-2483. [CrossRef] [PubMed]

39. Melotto, M.; Mecey, C.; Niu, Y.; Chung, H.S.; Katsir, L.; Yao, J.; Zeng, W.; Thines, B.; Staswick, P.; Browse, J.; et al. A critical role of two positively charged amino acids in the Jas motif of Arabidopsis JAZ proteins in mediating coronatine- and jasmonoyl isoleucine-dependent interactions with the COI1 F-box protein. Plant J. 2008, 55, 979-988. [CrossRef]

40. Chini, A.; Fonseca, S.; Chico, J.M.; Fernández-Calvo, P.; Solano, R. The ZIM domain mediates homo- and heteromeric interactions between Arabidopsis JAZ proteins. Plant J. 2009, 59, 77-87. [CrossRef]

41. Sheard, L.B.; Tan, X.; Mao, H.; Withers, J.; Ben-Nissan, G.; Hinds, T.R.; Kobayashi, Y.; Hsu, F.F.; Sharon, M.; Browse, J.; et al. Jasmonate perception by inositolphosphate-potentiated COI1-JAZ co-receptor. Nature 2010, 468, 400-405. [CrossRef]

42. Li, Y.; Qin, L.; Zhao, J.; Muhammad, T.; Cao, H.; Li, H.; Zhang, Y.; Liang, Y. SIMAPK3 enhances tolerance to tomato yellow leaf curl virus (TYLCV) by regulating salicylic acid and jasmonic acid signaling in tomato (Solanum lycopersicum). PLoS ONE 2017, 12, e0172466. [CrossRef]

43. Kenton, P.; Mur LA, J.; Draper, J. A requirement for calcium and protein phosphatase in the jasmonate-induced increase in tobacco leaf acid phosphatase specific activity. J. Exp. Bot. 1999, 50, 1331-1341. [CrossRef]

44. Santner, A.; Estelle, M. Recent advances and emerging trends in plant hormone signaling. Nature 2009, 459, 1071-1078. [CrossRef]

45. Fernández-Calvo, P.; Chini, A.; Fernández-Barbero, G.; Chico, J.M.; Gimenez-Ibanez, S.; Geerinck, J.; Eeckhout, D.; Schweizerd, F.; Godoy, M.; Franco-Zorrillae, J.M.; et al. The Arabidopsis bHLH transcription factors MYC3 and MYC4 are targets of JAZ repressors and act additively with MYC2 in the activation of jasmonate responses. Plant Cell 2011, 23, 701-715. [CrossRef]

46. Schmiesing, A.; Emonet, A.; Gouhier-Darimont, C.; Reymond, P. Arabidopsis MYC transcription factors are the target of hormonal salicylic acid/jasmonic acid cross talk in response to Pieris brassicae egg extract. Plant physiol. 2016, 170, 2432-2443. [CrossRef]

47. Figueroa, P.; Browse, J. Male sterility in Arabidopsis induced by overexpression of a MYC5-SRDX chimeric repressor. Plant J. 2015, 81, 849-860. [CrossRef]

48. Sasaki-Sekimoto, Y.; Jikumaru, Y.; Obayashi, T.; Saito, H.; Masuda, S.; Kamiya, Y.; Ohta, H.; Shirasu, K. Basic helix-loop-helix transcription factors JASMONATE-ASSOCIATED MYC2-LIKE1 (JAM1), JAM2, and JAM3 are negative regulators of jasmonate responses in Arabidopsis. Plant Physiol. 2013, 163, 291-304. [CrossRef]

49. Song, S.; Qi, T.; Huang, H.; Ren, Q.; Wu, D.; Chang, C.; Peng, W.; Liu, Y.; Peng, J.; Xie, D. The jasmonate-ZIM domain proteins interact with the R2R3-MYB transcription factors MYB21 and MYB24 to affect jasmonate-regulated stamen development in Arabidopsis. Plant Cell 2011, 23, 1000-1013. [CrossRef]

50. Qi, T.; Song, S.; Ren, Q.; Wu, D.; Huang, H.; Chen, Y.; Fan, M.; Peng, W.; Ren, C.; Xie, D. The jasmonate-ZIM-domain proteins interact with the WD-Repeat/bHLH/MYB complexes to regulate jasmonate-mediated anthocyanin accumulation and trichome initiation in Arabidopsis thaliana. Plant Cell 2011, 23, 1795-1814. [CrossRef] 
51. Zhou, M.; Sun, Z.; Ding, M.; Logacheva, M.D.; Kreft, I.; Wang, D.; Yan, M.; Shao, J.; Tang, Y.; Wu, Y.; et al. FtSAD2 and FtJAZ1 regulate the activity of FtMYB11 transcription repressor in phenylpropanoid pathway of Fagopyrum tataricum. New Phytol. 2017, 216, 814-828. [CrossRef] [PubMed]

52. Zhang, K.; Logacheva, M.D.; Meng, Y.; Hu, J.; Wan, D.; Li, L.; Dagmar, J.; Wang, Z.; Georgiev, M.I.; Yu, Z.; et al. Jasmonate-responsive MYB factors spatially repress rutin biosynthesis in Fagopyrum tataricum. J. Exp. Bot. 2018, 69, 1955-1966. [CrossRef] [PubMed]

53. Delessert, C.; Kazan, K.; Wilson, I.W.; van der Straeten, D.; Manners, J.; Dennis, E.S.; Dolferus, R. The transcription factor ATAF2 represses the expression of pathogenesis-related genes in Arabidopsis. Plant J. 2005, 43, 745-757. [CrossRef]

54. Nuruzzaman, M.; Sharoni, A.M.; Kikuchi, S. Roles of NAC transcription factors in the regulation of biotic and abiotic stress responses in plants. Front. Microbiol. 2013, 4, 248. [CrossRef] [PubMed]

55. Bu, Q.; Jiang, H.; Li, C.B.; Zhai, J.; Wu, X.; Sun, J.; Xie, Q.; Li, C. Role of the Arabidopsis thaliana NAC transcription factors ANAC019 and ANAC055 in regulating jasmonic acid-signaled defense responses. Cell Res. 2008, 18, 756-767. [CrossRef]

56. van der Fits, L.; Memelink, J. ORCA3, a jasmonate-responsive transcriptional regulator of plant primary and secondary metabolism. Science 2001, 289, 295-297. [CrossRef]

57. Lorenzo, O.; Piqueras, R.; Sánchez-Serrano, J.J.; Solano, R. ETHYLENE RESPONSE FACTOR1 integrates signals from ethylene and jasmonate pathways in plant defense. Plant Cell 2003, 15, 165-178. [CrossRef]

58. Pré, M.; Atallah, M.; Champion, A.; de Vos, M.; Pieterse, C.M.J.; Memelink, J. The AP2 /ERF domain transcription factor ORA59 integrates jasmonic acid and ethylene signals in plant defense. Plant Physiol. 2008, 147, 1347-1357. [CrossRef]

59. Li, J.; Zhang, K.; Meng, Y.; Hu, J.; Ding, M.; Bian, J.; Yan, M.; Han, J.; Zhou, M. Jasmonic acid/ethylene signaling coordinates hydroxycinnamic acid amides biosynthesis through ORA59 transcription factor. Plant J. 2018, 95, 444-457. [CrossRef]

60. Chen, H.Y.; Hsieh, E.J.; Cheng, M.C.; Chen, C.Y.; Hwang, S.Y.; Lin, T.P. ORA47 (octade-canoid-responsive AP2/ERF-domain transcription factor 47) regulates jasmonic acid and abscisic acid biosynthesis and signaling through binding to a novel cis-element. New Phytol. 2016, 211, 599-613. [CrossRef] [PubMed]

61. Fujimoto, S.Y.; Ohta, M.; Usui, A.; Shinshi, H.; Ohme-Takagi, M. Arabidopsis ethylene-responsive element binding factors act as transcriptional activators or repressors of GCC box-mediated gene expression. Plant Cell 2000, 12, 393-404. [CrossRef]

62. Li, J.; Zhong, R.; Palva, E.T. WRKY70 and its homolog WRKY54 negatively modulate the cell wall-associated defenses to necrotrophic pathogens in Arabidopsis. PLOS ONE 2017, 12, e0183731. [CrossRef]

63. Kloth, K.J.; Wiegers, G.L.; Busscher-Lange, J.; van Haarst, J.C.; Kruijer, M.; Bouwmeester, H.J.; Dicke, M.; Jongsma, M.A. AtWRKY22 promotes susceptibility to aphids and modulates salicylic acid and jasmonic acid signalling. J. Exp. Bot. 2016, 67, 3383-3396. [CrossRef]

64. Gao, Q.M.; Venugopal, S.; Navarre, D.; Kachroo, A. Low oleic acid-derived repression of jasmonic acid-inducible defense responses requires the WRKY50 and WRKY51 proteins. Plant Physiol. 2011, 155, 464-476. [CrossRef]

65. Jiang, Y.; Liang, G.; Yang, S.; Yu, D. Arabidopsis WRKY57 functions as a node of convergence for jasmonic acid-and auxin-mediated signaling in jasmonic acid-induced leaf senescence. Plant Cell 2014, 26, 230-245. [CrossRef]

66. Jiang, Y.; Guo, L.; Liu, R.; Jiao, B.; Ling, Z.; Luo, K. Overexpression of poplar PtrWRKY89 in transgenic Arabidopsis leads to a reduction of disease resistance by regulating defense-related genes in salicylate-and jasmonate-dependent signaling. PLoS ONE 2016, 11, e0149137. [CrossRef]

67. Skibbe, M.; Qu, N.; Galis, I.; Balawin, I.T. Induced plant defenses in the natural environment: Nicotiana attenuala WRKY3 and WRKY6 coordinate responses to herbivory. Plant Cell 2008, 20, 1984-2000. [CrossRef]

68. Mewis, I.; Schreiner, M.; Nguyen, C.N.; Krumbein, A.; Ulrichs, C.; Lohse, M.; Zrenner, R. UV-B irradiation changes specifically the secondary metabolite profile in broccoli sprouts: Induced signaling overlaps with defense response to biotic stressors. Plant Cell Physiol. 2012, 53, 1546-1560. [CrossRef]

69. Cerrudo, I.; Keller, M.M.; Cargnel, M.D.; Demkura, P.V.; Wit, M.; Patitucci, M.S.; Pierik, R.; Pieterse CM, J.; Ballaré, C.L. Low Red/Far-Red ratios reduce Arabidopsis resistance to Botrytis cinerea and jasmonate responses via a COI1-JAZ10-dependent, salicylic acid independent mechanism. Plant Physiol. 2012, 158, 2042-2052. [CrossRef] 
70. Gupta, N.; Prasad, V.B.R.; Chattopadhyay, S. LeMYC2 acts as a negative regulator of blue light mediated photomorphogenic growth, and promotes the growth of adult tomato plants. BMC Plant Boil. 2014, 14, 38. [CrossRef]

71. Svyatyna, K.; Riemann, M. Light-dependent regulation of the jasmonate pathway. Protoplasma 2012, 249, 137-145. [CrossRef]

72. Zhao, M.L.; Wang, J.N.; Shan, W.; Fan, J.G.; Kuang, J.F.; Wu, K.Q.; Li, X.P.; Chen, W.X.; He, F.Y.; Chen, J.Y.; et al. Induction of jasmonate signaling regulators MaMYC2s and their physical interactions with MaICE1 in methyl jasmonate-induced chilling tolerance in banana fruit. Plant Cell Environ. 2012, 36, 30-51. [CrossRef]

73. Li, S.; Yang, Y.; Zhang, Q.; Liu, N.; Xu, Q.; Hu, L. Differential physiological and metabolic response to low temperature in two zoysiagrass genotypes native to high and low latitude. PLOS ONE 2018, 13, e0198885. [CrossRef]

74. Sayyari, M.; Babalar, M.; Kalantari, S.; Martínez-Romero, D.; Guillén, F.; Serrano, M.; Valero, D. Vapour treatments with methyl salicylate or methyl jasmonate alleviated chilling injury and enhanced antioxidant potential during postharvest storage of pomegranates. Food Chem. 2011, 124, 964-970. [CrossRef]

75. Cao, S.F.; Zheng, Y.H.; Wang, K.T.; Jin, P.; Rui, H.J. Methyl jasmonate reduces chilling injury and enhances antioxidant enzyme activity in postharvest loquat fruit. Food Chem. 2009, 115, 1458-1463. [CrossRef]

76. González-Aguilar, G.A.; Fortiz, J.; Cruz, R.; Baez, R.; Wang, C.Y. Methyl jasmonate reduces chilling injury and maintains postharvest quality of mango fruit. J. Agric. Food Chem. 2000, 48, 515-519. [CrossRef] [PubMed]

77. González-Aguilar, G.A.; Tiznado-Hernández, M.E.; Zavaleta-Gatica, R.; Martínez-Téllez, M.A. Methyl jasmonate treatments reduce chilling injury and activate the defense response of guava fruits. Biochem. Bioph. Res. Commun. 2003, 313, 694-701.

78. Xu, Y.H.; Liao, Y.C.; Zhang, Z.; Liu, J.; Sun, P.W.; Gao, Z.H.; Sui, C.; Wei, J.H. Jasmonic acid is a crucial signal transducer in heat shock induced sesquiterpene formation in Aquilaria sinensis. Sci. Rep-UK 2016, 6, 21843. [CrossRef]

79. Balbi, V.; Devoto, A. Jasmonate signalling network in Arabidopsis thaliana: Crucial regulatory nodes and new physiological scenarios. New Phytologist. 2008, 177, 301-318. [CrossRef]

80. Ollas, C.; Hernando, B.; Arbona, V.; Gómez-Cadenas, A. Jasmonic acid transient accumulation is needed for abscisic acid increase in citrus roots under drought stress conditions. Physiol. Plantarum. 2013, 147, 296-306. [CrossRef] [PubMed]

81. Todaka, D.; Shinozaki, K.; Yamaguchi-Shinozaki, K. Recent advances in the dissection of drought-stress regulatory networks and strategies for development of drought-tolerant transgenic rice plants. Front. Plant Sci. 2015, 6, 84. [CrossRef] [PubMed]

82. Fu, J.; Wu, H.; Ma, S.; Xiang, D.; Liu, R.; Xiong, L. OsJAZ1 attenuates drought resistance by regulating JA and ABA signaling in rice. Front. Plant Sci. 2017, 8, 2108. [CrossRef]

83. Mohamed, H.I.; Latif, H.H. Improvement of drought tolerance of soybean plants by using methyl jasmonate. Physiol. Mol. Biol. Plants 2017, 23, 545-556. [CrossRef]

84. Wu, H.L.; Wu, X.L.; Li, Z.H.; Duan, L.S.; Zhang, M.C. Physiological evaluation of drought stress tolerance and recovery in cauliflower (Brassica oleracea L.) seedlings treated with methyl jasmonate and coronatine. J. Plant Growth Regul. 2012, 31, 113-123. [CrossRef]

85. Evans, N.H. Modulation of guard cell plasma membrane potassium currents by methyl jasmonate. Plant Physiol. 2003, 131, 8-11. [CrossRef]

86. Horton, R.F. Methyl jasmonate and transpiration in barley. Plant Physiol. 1991, 96, 1376-1378. [CrossRef] [PubMed]

87. Ellouzi, H.; Hamed, K.B.; Cela, J.; Müller, M.; Abdelly, C.; Munné-Bosch, S. Increased sensitivity to salt stress in tocopherol-deficient Arabidopsis mutants growing in a hydroponic system. Plant Signal Behav. 2013, 8, e23136. [CrossRef]

88. Pedranzani, H.; Racagni, G.; Alemano, S.; Miersch, O.; Ramírez, I.; Pea-Cortés, H.; Taleisnik, E.; Machado-Domenech, E.; Abdala, G. Salt tolerant tomato plants show increased levels of jasmonic acid. J. Plant Growth Regul. 2003, 41, 149-158. [CrossRef]

89. De Domenico, S.; Taurino, M.; Gallo, A.; Poltronieri, P.; Pastor, V.; Flors, V.; Santino, A. Oxylipin dynamics in Medicago truncatula in response to salt and wounding stresses. Physiol. Plant. 2019, 165, 198-208. [CrossRef] 
90. Molina, C.; Zaman-Allah, M.; Khan, F.; Fatnassi, N.; Horres, R.; Rotter, B.; Steinhauer, D.; Amenc, L.; Drevon, J.J.; Winter, P.; et al. The salt-responsive transcriptome of chickpea roots and nodules via deepSuperSAGE. BMC Plant Biol. 2011, 11, 31. [CrossRef]

91. Ismail, A.; Riemann, M.; Nick, P. The jasmonate pathway mediates salt tolerance in grapevines. J. Exp. Bot. 2012, 63, 2127-2139. [CrossRef]

92. Ballhorn, D.J.; Reisdorff, C.; Pfanz, H. Quantitative effects of enhanced $\mathrm{CO}_{2}$ on jasmonic acid induced plant volatiles of lima bean (Phaseolus lunatus L.). J. Appl. Bot. Food Qual. 2011, 84, 65-71.

93. Sun, Y.; Yin, J.; Cao, H.; Li, C.; Kang, L.; Ge, F. Elevated $\mathrm{CO}_{2}$ influences nematode-induced defense responses of tomato genotypes differing in the JA pathway. PLOS ONE 2011, 6, e19751. [CrossRef]

94. Overmyer, K.; Tuominen, H.; Kettunen, R.; Betz, C.; Langebartels, C.; Sandermann, H.J.; Kangasjārvi, J. Ozone-sensitive Arabidopsis rcd1 mutant reveals opposite roles for ethylene and jasmonate signaling pathways in regulating superoxide-dependent cell death. Plant Cell 2000, 12, 1849-1862. [CrossRef]

95. Kanna, M.; Tamaoki, M.; Kubo, A.; Nakajima, N.; Rakwal, R.; Agrawal, G.K.; Tamogami, S.; Ioki, M.; Ogawa, D.; Saji, H.; et al. Isolation of an ozone-sensitive and jasmonate-semi-insensitive Arabidopsis mutant (oji1). Plant Cell Physiol. 2003, 44, 1301-1310. [CrossRef]

96. Rao, M.V.; Lee, H.; Creelman, R.A.; Mullet, J.E.; Davis, K.R. Jasmonic acid signaling modulates ozone-induced hypersensitive cell death. Plant Cell 2000, 12, 1633-1646. [CrossRef]

97. Koch, J.R.; Creelman, R.A.; Eshita, S.M.; Seskar, M.; Mullet, J.E.; Davis, K.R. Ozone sensitivity in hybrid poplar correlates with insensitivity to both salicylic acid and jasmonic acid. The role of programmed cell death in lesion formation. Plant Physiol. 2000, 123, 487-496. [CrossRef]

98. Grantz, D.A.; Vu, H.B. Root and shoot gas exchange respond additively to moderate ozone and methyl jasmonate without induction of ethylene: Ethylene is induced at higher O3 concentrations. J. Exp. Bot. 2012, 63, 4303-4313. [CrossRef]

99. Devoto, A.; Ellis, C.; Magusin, A.; Chang, H.S.; Chilcott, C.; Zhu, T.; Turnter, J.G. Expression profiling reveals COI1 to be a key regulator of genes involved in wound- and methyl jasmonate induced secondary metabolism, defense and hormone interactions. Plant Mol. Biol. 2005, 58, 497-513. [CrossRef]

100. Chen Chen, Y.Z.; Pang, Q.Y.; Dai, S.J.; Wang, Y.; Chen, S.X.; Yan, X.F. Proteomic identification of differentially expressed proteins in Arabidopsis in response to methyl jasmonate. Plant Physiol. 2011, 168, 995-1008. [CrossRef] 